\title{
Gendered Voices in Children's Television Advertising
}

\author{
Fern L. Johnson and Karren Young
}

$\square$-Televised ads for toys directed to children were examined to address two research questions: (1) Do advertisers script language differently for females and males? and (2) How is gender used as a discourse code to link products to gender roles? In a sample from 1996, 1997, and 1999, ads for boy-oriented toys outnumbered those oriented to girls. In boy-oriented ads, the voice-overs were exclusively male, and in the girl-oriented ads, they were mainly female. Gender exaggeration in voice-overs was prevalent. Verb elements in the ads were also examined. Gender patterns were found in the types of verb elements used. Boy-oriented ads contained more elements emphasizing (1) action,(2) competition and destruction, and (3) agency and control. Girl-oriented ads contained more verb elements emphasizing (1) limited activity and (2) feelings and nurturing. The speaking roles scripted for girls and boys also revealed polarized gender voices and gender relations. Finally, the use of "power" words was prevalent in a number of ads targeted to boys but was absent in those targeted to girls. We concluded that the gender ideology underlying these ads portrays males and females through strikingly traditional gender-polarized voices, and we discuss the implications for teaching media literacy to children.

dvertising-on television, bill-
internet, in newspapers, magazines, and

Fern Johnson is Professor of English and Director of the Communication and Culture Program at Clark University. Karren Young is an independent filmmaker and production staff member at WYBE Public Television in Philadelphia. The research was supported in part by a Clark University Faculty Development Grant to the first author. An earlier version of this paper was presented at the Conference of the Organization for the Study of Communication, Language and Gender, Milwaukee, WI (October, 2000) The second author completed a portion of the analysis for a senior honors thesis at Clark University. We thank Sandra Zimmerman for her assistance and express appreciation to the reviewers for CSMC for their helpful guidance in strengthening the analysis. movie theatres-invades the consciousness of most everyone. Sponsors pay enormous amounts to place ads in those locations where the largest segment of the targeted audience is likely to see and hear them, and they rely on new, creative approaches both to instill and fuel the desire for more and more consumption. Although most ads target adult audiences, children make up an important audience. Children play with a vast array of toys and eat trendy foods and snacks-many of which are introduced to them through advertising. This non-adult market is the focus of this essay.

In a consumer-oriented culture, advertisers must position the products they represent as enhancements to both happiness and desirable life styles. Image serves as the link between product 
and consumer motivation: get the consumer to buy into the image associated with the product, and purchase becomes more likely. "In short," comments Sut Jhally (1995), "the advertising image-system constantly propels us toward things as means to satisfaction" (p. 80).

To keep the consumer system going, new strategies must be constantly invented to keep the buyer motivated to spend money, not only to replace old items or replicate product choices but also to stock the newest available goods and services. The pressure for newness of product and novelty of approach keeps the creative department of advertising agencies experimenting with novel strategies-strategies "over-thetop" of all that came before. The results often appear ludicrous, startling, and bewildering in their separation of the product from the gimmick used to gain and hold attention. Benetton, for example, topped its already over-thetop approaches with a mini-magazine focused on death row inmates inserted into the February 2000 issue of Talk. Nike went so far that it crossed the acceptability line during the 2000 Summer Olympics when it ran a slashertype scenario featuring a woman escaping from a tent in the forest with an attacker in pursuit whom she outruns because of her Nikes (the ad was pulled on September 19 because of numerous consumer complaints). Children's ads similarly present novel strategies, most often aimed at exploiting themes of fun and fantasy. In an ad for "Honey Comb Cereal," three kids are transformed into animal heads, and dad into a complete zombie with bug eyes whose easy chair becomes a hospital-like stretcher; the kids race off with dad to the supermarket where they empty the aisle of Honey Comb, heaping their grocery carts and speeding to an older woman checker who looks and acts like a punker. An ad for "Disney.com" shows a potato-chip-eating, bored boy being sucked into a computer screen to the craziness of the "z-ther zone"-a place where you "don't need clean underwear to go."

With the rapid modifications in ad presentations, consumers are just as likely to look for new ads as they are for new products. Indeed, Robert Goldman and Stephen Papson (1996) conclude their aptly titled book, Sign Wars: The Cluttered Landscape of Advertising, by saying:

The capitalist idea of overcoming barriers to capital circulation has bred a commodity culture driven by an amazingly rapid turnover of signifiers and signifieds. Free flying signifiers and signifieds are continuously recirculated into a still newer pastiche combo of the day. The combinations inflate, the combinations deflate, and the process starts again, hinging and unhinging signifiers and signifieds to define new signs. (p. 273)

Yet, beneath the creativity and innovation that produce new images, under the over-the-top visual and sound bite invitations, these ads contain many less discontinuous, less fragmented, less novel representations and stories: the "united colors" of Benetton exist in a culture where black men outnumber white men on death row; the Nike ad taps into the realities of rape and fear in women's lives; Honey Comb dramatizes children's wish for escape from their parents' rules about food so that they can consume loads of their favorites, and shows a story of dads so sufficiently inattentive that anything goes. And although Disney.com offers excitements not available in the "real world," this technological fantasy is packaged for boys, thus playing into the gender 
divide in technology use. The recognizable, more stable representations in ads anchor what is new with what is more enduring, essentially a tie to more deeply contoured cultural meanings that, on close examination, look markedly conventional. Indeed, such representations serve to reiterate and reinforce certain dominant ideologies. Not surprisingly, for-profit businesses capitalize on dominant ideologies even as they move elements of product promotion away from what we have come to expect in advertisements or storytelling more generally. Exploiting creative surfaces and more deeply embedded conservative ideologies, the parade of ever-interesting ads can simultaneously be short blasts of new representational forms and depictions of dominant ideology, especially in their representations of identity possibilities. Moreover, since the middle of the $20^{\text {th }}$ century, ads have been increasingly targeted to special audiences, each of which is a "segment" for potential profitability through consumption. Children are one of these special audiences.

\section{The Context for Marketing to Children}

Children are one market segment that has grown dramatically in importance (see Pecora, 1995). As initiates into consumer culture, kids are being cultivated to spend their own and their parents' money on a vast array of products-mainly in the toy, breakfast food, and snack categories. These three categories have not changed much over the years, but what has changed are increases in quantity and product differentiation, along with a more rapid pace in the presentation of new products. McNeal (1998) reported that children spent $\$ 23$ billion as consumers in 1997 , and he projected their spending would rise to $\$ 35$ billion by 2001 , with an additional direct influence on spending by parents of $\$ 300$ billion in response to the litany of "I want this!"-"Get me that!""Please Mommy/Daddy, please!""Here's my Christmas list."

Along with being cultivated as consumers, children are also the targets of what Jhally (1995) terms "image-based influence" (p. 81). One main type of image-based influence targets gender identity, and uses it to link products to their consumers. Even brief viewing of television commercials directed to children reveals the centrality of gender images as a source of meaning. These gender images display appearances and activities linked with gender. Based on our cursory examination, it appears that they also present an array of linguistic markers that bolster the more visually obvious gender representations; some of these linguistic markers can be heard easily while others are more subtle.

The purpose of the investigation reported here is to provide a critical examination of discourse in television commercials made for and marketed to children in order to determine the degree to which the language codes that are used call upon gender as a meaningful cultural category for selling. Two main questions are addressed, both of which direct a systematic critical inquiry regarding the ways in which linguistic markers function to define gender:

1. Do advertisers script language differently for females and males in ads directed to preschool and early elementary school boys and girls?

2. How is gender used as a discourse code to link products to gender roles? 


\section{Television as Cultural Resource for Children}

Children's television programming has been a major interest area among mass communication scholars for many years. As part of that interest, research on advertising to children has focused primarily on influence and effects, and the implications of these for regulation. Many of the research studies prior to 1990 are summarized in Young (1990). A recent volume devoted to children and advertising (Macklin \& Carlson, 1999) deals mainly with advertising impact as a complex social and cognitive process and with research on what the editors label the "two hot buttons" (p. xiii) in today's advertising to kids: cigarettes and alcohol. In a section of the book devoted to future directions in research, the authors emphasize newer media for advertising, such as the Internet, and refining audience research.

Although the case has been made repeatedly for the importance of understanding children's television in general and advertising in particular, we offer several points that are germane to the present investigation and that emphasize television's role as a cultural resource. First, ads for kids serve as training for consumer culture; hence, their role in enculturation and socialization should not be underestimated (Alexander \& Morrison, 1995). Through ads, kids learn that products for sale offer life style enhancements, fun, peer group status, and up-to-date coolness. In short, children's viewing of ads prepares them well for their roles as capitalist consumers. Advertisers target kids by appealing to their distinctiveness from adults and their power as "sovereign, playful, thinking consumers" (Kapur, 1999, p. 125). The ads children view on television invite them to project themselves into roles or to fantasize their play and responses to others in ways that are suggestive as to what kids should do.

Second, ads are increasingly part of the daily cultural environment of our lives. For today's children, ads are formative in that cultural environment more intensely and pervasively than ever before. Advertisers see the potential in the children's market, especially in the context of U.S. cultural patterns of spending and consumption far outpacing savings.

Third, ads directed to kids offer models for how to act, interact, and speak. Even when children recognize ads as fantasy, visions of enactment are planted as ideal images to strive toward. Children do, in fact, act out many of the ads they see on television, demonstrating mastery of both actions and words. Moreover, they can go a step further by taking the words or actions and placing them into a situation totally separated from the ad and its product-a practice that parents and elementary school teachers see repeatedly. The foot-kicking of a karate fighter toy, the head tilt of little girls playing with their Barbie dolls, and the mouthing of dialogue and slogans such as "get the power," "kids rule," or "happenin' hair" are examples of extrapolating commercials' content into play venues. Using Judith Butler's (1993) theory that gender is performatively constructed as a starting point, Meijer (1998) makes a similar point in her discussion of the "performative side of advertising." She discusses the role of ads in promoting certain cultural stories. This line of thinking bears similarities to the cultural indicators perspective of George Gerbner and others, which is anchored in the idea that television is the major storyteller of our time. 
Fourth, some of the models available in ads for children map onto the significant foci of dominant ideologygender, race, ethnicity, class. In the case of the present project, gender ideology in ads is used to sell kids not only the commodity in question but gender ideology itself. Ads, thus, are part of each child's learning about gender and accomplishing the cultural task of becoming, in Sandra Bem's (1993) words, a "gendered native."

Related to these arguments regarding the importance of understanding what children view as cultural inductees, advertising functions as broad cultural impact-impact contributing to the enculturation of children through the cultural codes used to present products. We are especially interested in what the discourse elements of ads contribute to the cultural milieu of kids and to their available models for gender enactments. What forms of discourse are given to boys and girls? What aspects of verbal language give gendered meaning to products, to the actors in the commercials, and ultimately to the child viewer who is becoming, among other things, a gendered native of her or his culture?

\section{Gender Codes in Children's Advertising}

Past research on television commercials directed to children has shown that conventional sex roles underlie the content of many ads. Smith (1994) analyzed ads aired on children's programming in 1991 and found ads featuring only one sex or the other to be sex-role stereotypical. He concluded that when "advertisements only show traditional sex roles, they limit the range of experiences that children can try out" (p. 335). Furnham, Abramsky, and Gunter (1997), who studied U.S. and British commercials directed to children, concluded too that gender stereotyping "remains the dominant advertising form" (p. 97). These conclusions are entirely consistent with research on children's television programs. Thompson and Zerbinos (1995) provide a useful overview of gender patterns in programming as background for their study of gender roles in animated cartoons. In their study of 175 episodes from 41 different cartoon programs, they found both that male leads significantly outnumbered female leads (99 percent to 55 percent), and that male and female characters portrayed gender stereotypic roles.

Gender roles are portrayed partly through the ways in which scenes are framed and timed and in aspects of presentation not always readily apparent. These more subtle codes were examined by Welch, Huston-Stein, Wright, and Plehal (1979) who focused on the level of action or activity, pace, visual and camera techniques, and auditory techniques in a sample of toy commercials directed at three target audiences: boys, girls, and both boys and girls. Among their findings were more variability in the form of changes from scene to scene and more camera cuts in the boy-oriented commercials compared to the other two target groups. Commercials targeted to girls contained more fades and dissolves. Especially relevant to the present study, these researchers found that girls talked less than did boys in the commercials that target both girls and boys, but they talked a lot in those commercials targeted only to girls. These researchers conclude that, "the messages about masculine and feminine behavior conveyed by the features measured here may be more influential [because they 
are subtle] than the blatant stereotypes presented in the content" (p. 208).

Despite some noticeable differences in recent ads directed to kids-especially in the more frequent, but still minimal, inclusion of children of color-we speculated based on our own viewing that a close examination would show more recent ads to be strikingly traditional in portraying polarized gender codes. In an era when the metaphor of "level playing field" is frequently used, and in the context of greater attention to girls and the "GIRL POWER!" movement, one might expect more enlightened representations than are seen in the typical ads presented to children. We will, however, demonstrate through several characterizations of language contained in ads directed to children that the underlying ideology for the discourse scripted into these ads presents verbal images of gender that conform to blatantly traditional recipes for enacting and performing a gendered life. These images engage discourses that position girls (and women) in constrained positions and boys (and men) in action-oriented positions. As recipes, the ads turn out sweet girls and wild boys.

\section{Television Ads as Cultural Environment}

It has long been established that television contributes to the cultural environment of children. Data have been available for a number of years about the time that children spend per week watching television-mainly commercial television. Ads comprise an alarming proportion of that viewing time. Research conducted on over 10,000 ads taken from seven television program sources in early 1990 by Kunkle and Gantz (1992) showed a range of 10:24 minutes (Nickelodeon) to 13:26 minutes (independent stations) of advertising per hour of children's programming. The 1990 Children's Television Act regulated the amount of air-time that can be devoted to commercials: 12 minutes per hour on weekdays and 10.5 minutes per hour on weekends. Most ads run for 30 seconds, with a few 15 -second spots appearing also.

A simple calculation shows the magnitude of kids' exposure to commercials. The regulated advertising limits calculated as the number of 30 -second ads possible in an hour of children's viewing time equal 24 ads per hour on weekdays and 21 per hour on weekend days. If a child watches just one hour of commercial television per day, that child would likely be exposed to at least 160 ads each week. If a child watches what has been reported as the average of two and one-half hours per day (Woodard, 2000), she or he would likely be exposed to about 400 ads each week-many in this number repeated over and over during the week. Young children tend to rivet their attention on ads and look forward to their appearance in the programs they watch. Children at different ages understand and give meaning to ads differently (see John, 1999), but regardless of age, ads stick with kids. Producers of children's programming and advertisers catering to kids know that creating a child-oriented television milieu boosts profitability. "Young children," says Stephen Kline (1993), “. . . clearly get exposed to many ideas about social life from this specifically child-oriented programming and advertising" (p. 73).

To learn more about the broad themes and more specific discourse styles relevant to what children might be learning about gender from televised commercials, ads broadcast on 
TABLE 1

DISTRIBUTION OF COMMERCIALS

\begin{tabular}{lcccc}
\hline \hline \multicolumn{1}{c}{ Category } & Sample 1 & Sample 2 & Sample 3 & \\
& $\mathbf{1 9 9 6}$ & $\mathbf{1 9 9 7}$ & $\mathbf{1 9 9 9}$ & Combined \\
\hline Food, drink, snack items & $47.7 \%(71)$ & $41.4 \%(55)$ & $45.9 \%(90)$ & $45.2 \%(216)$ \\
Toys & $42.3 \%(63)$ & $42.9 \%(57)$ & $34.7 \%(68)$ & $39.3 \%(188)$ \\
Educational and public service & $3.4 \%(5)$ & $7.5 \%(10)$ & $3.1 \%(6)$ & $4.3 \%(21)$ \\
Recreation & $2.7 \%(4)$ & $2.3 \%(3)$ & $6.1 \%(12)$ & $4.0 \%(19)$ \\
Video and movie promotions & $4.0 \%(6)$ & $6.0 \%(8)$ & $3.1 \%(6)$ & $4.2 \%(20)$ \\
Other & $\mathrm{NA}$ & $\mathrm{NA}$ & $7.1 \%(14)$ & $2.9 \%(14)$ \\
Total & 149 & 133 & 196 & 478 \\
\hline \hline
\end{tabular}

different types of television channels were collected for analysis. Emphasis was placed on elements of the gendered voice, specifically on four aspects: voice-overs, verb elements, speaking lines given to girls and boys, and the conspicuous use of the word power in a number of ads oriented to boys.

\section{Content and Discourse Analysis Study}

\section{Sample of Commercials}

Samples of children's television programs in the cartoon genre were video recorded from commercial networks, regional independent New England stations, and Nickelodeon in the fall of 1996 and 1997 and again in the fall of 1999. We chose the three different program sources to ensure that the sample included advertisements from a broad range of cartoon programs (the Disney Channel and the Cartoon Network were not included because at the time the sample was collected, they were premium cable selections in the regional market and, thus, available only through expanded cable subscription). The 1999 sample was added to the original two-year sample so that we could check for any differences that might have occurred in the gender targeting of commercials.
Fifteen half-hour programs were taped for fall 1996 and fall 1997, and 24 half-hour programs were taped in fall 1999 (actual time for each program is approximately 27 minutes because of commercial and station content between programs). The total number of commercials included within the time boundaries marking the beginning and ending of the programs, exclusive of network and station promotions, was 478 (149 for the 1996 programs; 133 for the 1997 programs; 196 for the 1999 programs). The range of commercials per program was 8.2 to 8.9 (commercials aired between programs were not included in the analysis).

The ads were classified in one of five product categories (see Table 1): (1) food items, mainly breakfast cereals, snacks, and drinks; (2) toys; (3) educational and public service announcements, such as anti-drug messages; (4) recreational facilities or locales, such as "Water Country" and "Chuck E. Cheese's," and fast food restaurants, such as McDonalds; and (5) video and movie promotions. The 1999 sample included additional ads for adult products and miscellaneous services, which were coded as (6) other. The most surprising ads in this category were for "VISA Card" and "Ford Trucks," both adult products; the VISA card promo was scripted as a comedy about a man 
who gets locked in the bathroom of his woman friend's glamorous apartment. The woman eventually gets a locksmith by using her VISA card, but not until her man has given himself a facial-all of which seems to be a genderlinked humorous appeal for young children to think about credit cards and what you can do with them when you have no cash.

Commercials promoting toys made up 39.3 percent of the sample-somewhat more than the proportion of toy commercials in the sample collected by Kunkle and Gantz's (1992) in 1990. In the 1990 sample, 33.8 percent of the ads were for toys. Using this data as a comparison point, we found a greater proportion of toy ads in 1996 and 1997 (42.3\% and $42.9 \%$, respectively) but a similar proportion (34.7\%) in the 1999 ads. The higher percentage of toy ads in both 1996 and 1997 was likely influenced by pre-holiday fall promotions for toys in contrast to the 1990 sample which was collected in February. Increased promotion of toys as commodities may also have led to more ads in this category. The decrease in the proportion of toy ads in 1999 compared to 1996 and 1997 is less easy to explain. One factor contributing to this lower proportion is the lesser number of "Barbie" ads, which may have resulted from the impact of an unsuccessful shift to technology-related Barbie products, corporate losses, and an executive shake-up at Mattel Toys (see White, 1999).

\section{Analysis of Toy Commercials}

The commercials for toys were selected as the focus for analysis. Of the 188 such ads broadcast during the sample period, there were 147 different ads (that is, 22 percent were re- peats). Toy ads were selected for several reasons: they are the most expensive commodity for sale on kids' television; they are the product most amenable to gender elaboration and segmentation; and they are the currency of cultural "stuff"-and as such, the training ground for the inclination to buy the newest products available.

The toy ads were transcribed and categorized by their gender target audience using three categories: (1) ads targeted to boys in which boys were depicted, (2) ads targeted to girls in which girls were depicted, and (2) ads targeted to both boys and girls either because both genders were featured or because there was no gender content. Categorizing ads in this manner proved straightforward. We did, however, add two criteria to clarify the categorization scheme. First, the gender of the children portrayed rather than the nature of the toy itself guided the coding. Thus, for example, an ad for "Frisbee Bowling" featuring only boys was coded as boy-oriented even though the product itself carries no clear gender link to boys. Second, ads explicitly oriented to one gender rather than the other were coded as such even if a child of the other gender was included either in the background or for a few seconds. These were judged to be "gratuitous," token gender representations and not explicit market orientations. Nine ads (4.8 percent) in which girls could be seen were classified as "boy oriented" because the girls in these ads were either completely in the background or were hard to detect without replaying of the ads. For example, a "Super Soaker" water gun ad showed a girl in the background for about three seconds but featured boys in the central roles and included an aggressive male voice-over. There was only one 
TABLE 2

GENDER ORIENTATION OF TOY COMMERCIALS

\begin{tabular}{ccccc}
\hline \hline Gender Orientation & $\mathbf{1 9 9 6}$ & $\mathbf{1 9 9 7}$ & $\mathbf{1 9 9 9}$ & Combined \\
\hline Boy oriented & $47.6 \%(30)$ & $42.1 \%(24)$ & $70.6 \%(48)$ & $54.8 \%(103)$ \\
Girl oriented & $30.2 \%(19)$ & $49.1 \%(28)$ & $23.5 \%(16)$ & $33.0 \%(62)$ \\
Boy \& girl & $22.2 \%(14)$ & $8.8 \%(5)$ & $5.9 \%(4)$ & $12.2 \%(23)$ \\
Total & $\mathrm{n}=63$ & $\mathrm{n}=57$ & $\mathrm{n}=68$ & $\mathrm{n}=188$ \\
\hline \hline
\end{tabular}

example of a gratuitous token boy, which occurred in an ad from the 1999 sample for a hand-held "Friend Link" toy; in this case, the boy was the object of the girls messaging to one another.

Overall, boy-oriented ads exceeded girl-oriented ads, and there were relatively few ads directed to both girls and boys, $x^{2}(4)=19.72, p<.001$ (see Table 2). Differences in gender-orientation did, however, appear for the three years sampled. For 1996, boy-oriented ads outnumbered girl-oriented and boy/girl-oriented ads. For 1997, the boy-oriented and girl-oriented ads were similar in number but greater than boy/ girl-oriented ads. For 1999, boy-oriented ads heavily dominated the sample. Because our interest centers on gender representations in language and not on sample year attributes, we grouped all commercials together for subsequent analysis.

The names of many of the advertised toys vividly position verbal images of boys and girls in their cultural context. The act of naming linguistically engages semantic notions that reinforce gender polarization and direct attention to certain attributes of gender ideologies. "Big Time Action Heroes" and "Tonka Mega Crew," for instance, stress size as critical in these maleoriented toys, while "Juice 'n Cookies Baby Alive" and "Bedtime Bottle Baby" signify parenting as a female-linked quality. A sampling of toy names appears in Table 3.

For purposes of understanding what emphasis was being taken in the consumer development of boys and girls, we also looked at the type of toys being

TABLE 3

SAMPLE TOY NAMES BY GENDER ORIENTATION

\begin{tabular}{ll}
\hline \hline \multicolumn{1}{c}{ Boy-Oriented Toys } & \multicolumn{1}{c}{ Girl-Oriented Toys } \\
\hline Dragon Flyz & Take Care of Me Twins \\
Big Time Action Hero & Fluffy My Come Here Puppy \\
Electronic Karate Fighters & Juice 'n Cookies Baby Alive \\
Beast Wars Transformers & Girl Talk \\
Mars Attack Action Figures & Star Fairies \\
Total Justice Super Heroes & California Roller Girl \\
Super Man-The New Adventures Video Game & Clueless Fashion and Makeup Dear Diary \\
Tonka Magna Crew & Tea Bunnies \\
Play Doh Demolition Derby & Fashion Magic Fingernail Fun Salon Set \\
War Planets & Bedtime Bottle Baby \\
Super Soaker Extra Power Water Gun & Star Castles Light Up Gem Stone and \\
Anamorphs Transformers & Seashell Castles \\
Vortex Power Bat & Bowling Party Stacie \\
Super Sonic Power Crash Pit Racers & Friend Link \\
& Potty Dotty \\
\hline \hline
\end{tabular}


advertised. The toys were placed into categories based on their type (dolls, trucks, games, etc.), which were defined more specifically to better describe the products for sale. Although a range of toys was promoted in the ads, several types dominated. For boys, action figures such as Karate Fighters and Star Wars characters were most common (37 percent of the boy-oriented toys). Also of note was the rise in 1999 of emphasis on hand-held electronic games and computer related toys ("Game Boy" for example): 16 such ads appeared in the 1999 sample, compared to one in 1997 and none in 1996. For girl-oriented toys, the most common categories were what we labeled "posable figures"-Barbie Dolls being the most common, but also including animal figures-which comprised 44 percent of the toys promoted. Unlike action figures, these posable figures are shown being placed in scenes with little or no action. This type of category difference in the toys marketed to boys and to girls reinforces traditionally polarized ideas about the play activities of boys and girls.

\section{Dimensions of Gendered Language in Toy Ads}

\section{Voice-Overs}

The dominance of male voice-overs in television commercials has been well documented (see Allan \& Coltrane, 1996), and we did not expect to hear departures in the ads we analyzed. The faceless but not genderless person behind the voice provides information, urges consumers to pursue the product, and sometimes makes disclaimers about the product or its packaging and appearance. To determine the particular patterns in gendered aspects of voice-overs in ads directed to kids, we considered two attributes of the voiceovers: (1) the gender of the voice-over and (2) whether the voice-over was gender-exaggerated.

All of the commercials in the sample included voice-overs. A male voiceover was heard in every one of the boy-oriented and the boy/girl-oriented ads. The vast majority $(89 \%)$ of the voice-overs in girl-oriented ads contained female voices, but there were some with male voices. Four ads oriented to girls contained both a female and a male voice-over. In all but twelve commercials, the voices heard were those of adults. Of the twelve nonadult voice-overs, a girl's voice was heard in eight girl-oriented ads, and a boy's voice in only one ad oriented to boys (those oriented to both boys and girls included one boy's voice-over and one in which both boys and girls were heard). Based on these patterns, the use of voice-overs appears to follow a simple rule: sex of the voice-over should generally be matched to sex of the target for the toy, but the male voice-over may be used in ads targeted to girls and must be present in ads targeted to both sexes.

Anyone who has listened to the voice-overs in ads directed to kids knows that some rather strange sounds are emitted from the faceless speakers. The voices often sound stylized to create a particular quality associated with the play that is to be imagined by the child. Amid more normal sounding voices, we hear unnaturally deep, husky voices; voices that sound like growls; squeaky, high-pitched voices; voices with a sing-song quality; voices sounding out of control. To understand the degree of gender voice stylization and exaggeration present in the voiceovers, we characterized each voice- 
over as either "normal sounding" or as "gender exaggerated"; in a couple of cases, animal voices were used, which were noted as "other." For male voiceovers, we listened for exaggerated masculine and/or aggressive voice qualities. For female voice-overs, we listened for exaggerated feminine, high pitched and/or sing-song voice qualities. A third person not involved in the project listened to 20 voice-overs and characterized all of them in the same way that we did.

Exaggerated gender stylization was prevalent in the voice-overs used in commercials for both boy-oriented and girl-oriented toys $(80 \%$ and $87 \%$, respectively). Gender stylization in presentation of the voice-overs was not common in the few commercials for toys pitched to both girls and boys.

It seems that advertisers, when constructing voice-overs, strive to accentuate gender, sometimes to the point of caricature. The male voices are too wild and loud, and the female voices are too high pitched and singsong. Although adults might perceive these voices as caricatures, children-especially those in pre- and early elementary school-likely interpret them more directly. From a critical perspective, the exaggeration, even if playful, serves to stabilize polarized images of the gendered voice and may also contribute to attitudes and stereotypes about how females and males sound. The exaggeration is precisely what we hear in the mimicking of gendered voices, especially when males imitate the female voice.

\section{Gendered Verb Elements}

Verbs and their associated words contain a rich semiotic map that provides clues to the nature of agency, action, and type of activity. As children develop language, their understanding and use of more complex verb systems also develops. For pre-school children, verbs play an important role in both directing and commenting on activity and action. Classic examples of selfdirected speech demonstrate this aspect of children's language, for instance, in expressions such as "throw ball" when the child is throwing the ball or "push it" when the child is pushing a toy across the floor. Play activities for this age group and older are replete with verbs to accompany the action. Because actions engage particular connotations in the context of a cultural system that underlies the naming of activity and action through language, the semantic "text" for any verb includes much more than the action or state itself. Thus, verbs, like other aspects of language, contain "semantic notions" (Johnson, 2000, p. 36). These semantic notions encompass the cultural connotations and ideological meanings that develop over time with use of the verb in context. In a democratic society, the verb "dictate," for example, might suggest something that takes away another's freedom and autonomy; in a culture saturated with violence, "smash" might suggest meanings related to aggression and destruction of property; and "nurture" extends beyond the protective development of infants and children to more public facilitation of the development of others by teachers, coaches, and managers in the workplace.

To gauge the role of verb elements in creating a gendered voice in ads directed to children, the transcriptions for ads that had been coded as either girl-oriented or boy-oriented were examined for their verb elements. All verbs were considered except those in the "TO BE" copula forms ("is," "are," 
etc.). From that examination, five categories were developed to distinguish particular types of verb elements that might be relevant for gender imaging. Emphasis is used in the text to highlight the particular attribute.

1. action verb elements, which are defined as those verbs that relate to physical movement or motion, usually associated with an agent

Examples: crawl, fly, jump, race, ram, throw

Sample: from ad for "RC MEGA RACING"

steer em, pass em, rough it up ride the rails

hit a jump and throw a block speed up and take-off

flip over and keep on movin

2. competition/destruction verb elements, which are a particular case of action verbs, directly relate to competitive action or to destructive movements or behavior

Examples: crush, fire on, knocked out, pounce, slam, stomp [your opponent] Sample: from ad for "K'NEX BREAKAWAY SPEEDSTERS"

first you make em

then you break em

smash em up

break em smash em feel the power

3. agency/control verb elements, which are defined as verbs referring to the target consumer or the speaker in the commercial as one who possesses power over someone else or something else, or who acts as a cause or catalyst for change

Examples: control, defeat, rule, take Sample: from ad for "WAR PLANETS”

you transform planet rock into a mighty war planet you construct generator nodes to form the ultimate war planet of unlimited power
4. limited activity verb elements, which are defined as verbs or verb elements that signify an activity or state of being that does not involve explicit physical movement linking the person to an action indicated in the verb, even though some motion may be involved

Examples: beware, get, go, know, look, talk, wait, watch

Sample: from ad for "FRIENDSHIP LINK"

just look and see

and you might find

that perfect friend

who's just like you

5. feeling and nurturing verb elements, which are a special case of limited activity verb elements, are specific in their orientation to emotions and caring

Examples: cuddle, loves, taking care of, tuck you in

Sample: from ad for "TAKE-CAREOF-ME TWINS"

take-care-of-me twins

keep me on the run

but caring for twins

is so much more fun

The types of verb elements used in the different target audience groups were analyzed to see if the semantic notions engaged through these verbs differ in the boy-oriented and girloriented ads. Although our concern was not with analysis of the quantitative distribution of language elements, frequency counts are provided to underscore the prevalence and magnitude of themes in the verbal images presented. These counts should be interpreted in the context of the higher number of boy-oriented than girl-oriented ads (the ratio is $1.66: 1$ ). The frequency counts for verb element types appear in Table 4 and show clear gender-linked patterns, $x^{2}(3)=165.99$, 
TABLE 4

FREQUENCY OF VERB ELEMENT

TYPE BY GENDER ORIENTATION OF COMMERCIAL

\begin{tabular}{lcc}
\hline \hline \multicolumn{1}{c}{$\begin{array}{c}\text { Verb Element } \\
\text { Type }\end{array}$} & $\begin{array}{c}\text { Boy- } \\
\text { Oriented }\end{array}$ & $\begin{array}{c}\text { Girl- } \\
\text { Oriented }\end{array}$ \\
\hline Action & 68 & 51 \\
Competition destruction & 113 & 9 \\
Agency and control & 103 & 24 \\
Limited activity & 151 & 268 \\
Feelings nurturing & 0 & 66 \\
\hline \hline
\end{tabular}

$p<.001$ (FEELINGS and NURTURING verb elements were excluded from the chi-square analysis because the cell size for boy-oriented ads is zero).

Several patterns stand out when we look at verb element types. First, the most conspicuous among the verb elements is the large difference in FEELINGS and NURTURING verb elements between boy-oriented and girloriented ads, $x^{2}(1)=33, p<.0000$. These elements are completely absent in the ads for boy-oriented toys. In comparison, scripts cultivating the female voice of nurturance are replete with the verb "love" (and "loves"). A number of nurturing verbs also clustered around the role of mothering and taking care of baby dolls just as a mommy would care for her baby, or in some cases, mothering words by an adult female shown in the ad. "Feed," "cuddle," "tuck in," "bathes," and "care" typify this type of semantic orientation.

A second pattern of gender polarization emerged for verb elements related to COMPETITION and DESTRUCTION, which are heard frequently in ads for boy-oriented toys, $x^{2}(1)=$ 44.33, $p<.0000$. The boy-oriented ads contain over twelve times as many of these verb elements as do the girloriented ads. Across the three sample years, scripts cultivating the male voice loudly proclaim the semantic notions of competition and destruction with verb elements such as "bash," "battle," "compete," "rammed," "rumbled," "slash," "smash," "toppled," and "wreck."

The competition/destruction verbs heard in girl-oriented commercials suggest less intensity and out-of-control activity. "Win" was heard in an ad for "OLYMPIC GYMNAST BARBIE" in which we see the quintessential girls' sport-individually oriented and associated with eating disorders. "Break" occurs in an ad for "TALK BACK DEAR DIARY" and refers not to something the girls do but to an action taken by boys who tried to "break into" the girl's old diary. In the 1999 sample, three of the four verbs in the competition/destruction category were uttered by a gratuitous boy who appears in ads for "BOWLING PARTY STACIE": after lurking in the background while two girls play with the game, he grabs the Stacie doll when the girls leave the room and commands her to "slam" the bowling pins. These latter two examples reinforce gender polarization because the boys in the ad are the ones who voice the competition/destruction verbs.

Third, verb elements associated with LIMITED ACTIVITY are strikingly more present in ads targeted to girls than in those targeted to boys, $x^{2}(1)=$ $16.34, p<.001$. Even though boytargeted ads contain a reasonably high number of these verb elements, words of this type are much more prevalent in the girl-targeted ads. The most frequent limited activity verb elements for girls were "come," "got," "go," "believe," and "look." For boys they were "watch," "go," "need," and "get."

A fourth pattern was for AGENCY and CONTROL verb elements to be more prevalent in the ads for boy- 
oriented toys than in those for girloriented toys, $x^{2}(1)=24.57, p<.0001$. The ratio of these elements in boyoriented compared to girl-oriented ads was in excess of $4: 1$. In the boy-oriented ads, many different agency/control verbs occurred; the more frequent ones were "rule," "control," "drive," “change," "stop" (as in "stop the alien invasion" from an ad for "ANAMORPHS THE TRANSFORMERS"), and "take over." Many of these verb elements expressed strong forms of agency and control and often occurred in conjunction with verb elements of competition/destruction. In contrast, the agency/control elements in girl-oriented ads suggested weaker semantic agency/control: the most common verbs were variations of "to make," plus "create," "take," and "change" (which can express strong or weak agency depending on its context).

The verb elements in the category of ACTION showed less variation by gender-orientation of the commercial. Because all toy ads appeal to the child's fantasy of doing something with the commodity object for sale, this is not surprising. Indeed, variations on the verb "fly" occurred as the most common action verb across the samples. Yet, there are some differences in the verbal images suggested by the particular action verb elements used in the boy-oriented and girl-oriented ads. In the boy-oriented ads, we tend to hear verbs such as "pass," "throw," "take off," "zoom," "flip," and "fire on." The verbal imaging associated with girlappropriate physical activities and actions engaged less intense forms: variations of "skip," "walk," "twirl," "move," "dance," "stroll," and "check out" (as in "check out Happenin' Hair Barbie").

Putting these verb categories together, children hear a consistent difference in the images of the gendered voice that are created. Looking at the ads without hearing them reveals one part of the gender polarization process because we see girls and boys presented quite differently-doing different things, associated with different toys, wearing different types of clothing, and so forth. These visual aspects are relatively easy to point out to even an untrained viewer. When it comes to listening, many aspects of the verbal imaging process are more difficult to hear; it is unlikely, for instance, that specific verbs would be recalled in the same way as might be the hair color of a character or the scene in which a child is shown playing with a toy. Yet, these more subtle gender cues constitute aspects of gendered discourse.

\section{The Speaking Roles of Girls and Boys}

That women are talkers and men doers is a persistent Western cultural belief. This, of course, is a far too general assumption, but it persists in the folk linguistic domain. Indeed, there is some evidence that women, compared to men, use language more as a resource and more as a legitimate activity in and of itself (see Johnson, 1996; Walker, 1994). Yet, evidence also shows that women are conversationally dominated by men in some contexts related to work and decisionmaking and that they may even fall silent when persistently cut short (see Romaine, 1999, Ch. 6; West, 1992). In the cultural contexts in which language is used, variations will occur in gender related patterns of dominance, talkativeness, and silence. It is useful, however, to ask what models of gendered talk occur in the commercials that children watch and hear. Do advertisers script speech similarly for girls and boys, or is a gendered representation 
of talk advanced? What happens when boys and girls are placed together in commercials? Do they talk equally? In similar ways? To address these questions, we examined the speaking roles in the sample considered for this project.

Of the 188 ads, 41 percent (78) included speaking turns. A speaking turn was defined as a verbal utterance by an on-screen character. The boundaries of a turn were marked by the beginning and end of continuous speaking by an on-screen character; thus, a turn could end when another on-screen character began speaking, when a voice-over began, or when action or music rather than speaking was featured.

More than half of the girl-oriented and the boy/girl-oriented ads contained speaking turns (55 percent and 53 percent, respectively), compared to the boy-oriented ads, where only 26 percent included speaking lines, $x^{2}(2)=69.73, p<.0000$. If this sample is typical of what children are exposed to when they watch ads within cartoon programming, they are being presented with verbal models that reinforce the language stereotype that girls (and women) engage in talk while boys (and men) prefer action to words.

In those commercials where boys and girls appear together (which are most often for games), we have an opportunity to see and hear models of gender relations. Many of these ads demonstrated clearly scripted elements of gender relations-in all cases elements that polarize boys and girls. One of these is a girl-oriented ad, shown during "Scooby Doo," for a board game called Girl Talk; in this game, the players draw cards that instruct them to do certain things or to take a penalty "zit sticker." The comments of two young teen boys, shown in black and white at their school lockers, are interspersed into the scene of four girls, shown in color, playing the game in a girl's bedroom. The comments that the boys make about the girls are immediately contradicted by the girls' discourse while playing the game, conveying the idea that girls, when left to themselves, engage in trivial, child-like games and gossip. All characters in the commercial are white with the exception of Girl 3 who is African American (and has only a supporting speaking role in which she latches a remark onto the statement of another girl).

Boy 1: Kelly's not goofy like other girls

Girl 1:I play to win! [as Kelly jumps around doing the chicken]

...

Boy 2: Susan's more sophisticated

Girl 2: [reading from a game card] "Call a guy and tell him something gross." Never! I'll take a zit-sticker [Susan puts a zit-sticker on her face]

Boy 1: Kelly would never kiss and tell

Girl 1: My first kiss? Sure, I'll talk about it. It was at the movies.

Girl 1: I'm a winner/

Girl 3: /and a flirt a gossip and boy crazy

Girl 1: can we talk about this?

The name of the game itself announces the separation of girls and boys, using the well established semantic notion of girl talk as a cultural form to sell the game. The boys appear to be older than the girls, and the camera angle on them is from below, which enhances their stature. Contrary to the images of boys in many boy-oriented ads, the boys in this ad appear in control of themselves and reasonably mature. This is clearly an early-teen dating 
scene packed with gender codes, and its placement in a cartoon program directed at younger children gives it a clear socialization function.

Another example of how gender relations are represented in discourse is taken from a commercial for the board game Trouble. This ad shows two girls and two boys playing the game. Both boys speak in the ad. One girl is completely silent, and the other utters only the affirmation of "Yeah" followed by a giggle in response to one of the boys' remarks that "It's fun getting into trouble."

In the ads oriented to both girls and boys that include speaking lines, boys had more speaking turns than girls. In these 23 ads, girls spoke in five ads: one speaking turn in four ads, and two turns in one ad. The boys characters spoke in 9 ads: one speaking turn in three ads, two turns in three ads, and three turns in four ads. The sample is small, but it appears that boys are given more speaking roles in these ads than are girls. Also, when both girls and boys speak in an ad, girls speak only in response to the actions or statements of boys; for example, in an ad for the game Trouble with four speaking lines, the single girl speaker orients to the boys' comments:

Boy 1: hey want to get into trouble?

Boy 2: yeah, it's fun getting into trouble

Girl: yeah [giggles]

Boy 1: back to start

This is a classic case of male control of discourse.

\section{"Power" Discourse}

Other aspects in the discourse codes likely differentiate images of the female and male voice in similar ways. For example, the use of caption- ing in boy-oriented ads-often in capital letters and with exclamation points-emphasizes certain verbal elements and visually stresses certain aspects of the male paralinguistic prototype. The effect looks very much like an overdone PowerPoint presentation with words popping up, jumping, and flying about on the screen. The words "power" and "mega" run through many of the boy-oriented toy ads. The use of the word "power" in ads oriented to boys was so conspicuous that it caught our attention early in the project.

No other attribute typifies traditional conceptions of maleness in relationship to femaleness more than the uneven balance of power favoring males. Power is thought of both as a relationship attribute, as in "He holds all the power in the relationship," and as an individual attribute, sometimes in the context of others, as in "He is a powerful leader," and sometimes more self-contained as in "He has powerful strength." Even in the more self-contained sense of power, the underlying semantic notion contains meaning related to relationships. To have power is to have the potential to use it with other people, to be in an unequal power relationship with other people, or to act upon things. Power can also be associated with objects, which by implication will transfer this quality to humans if they possess or use these objects; a good example of this is the naming of the energy snack food "Power Bar" with its implication that eating the food will give the consumer more power. Linguistically, "power" is most often used as a noun or adjective and is commonly also used as the base for the word "powerful." As a noun, power is a thing to 
possess, essentially a static imposition of a state that is given cultural meaning. To hold power is literally to hold nothing, but the semantic notion of power utilizes power as a metaphor to "thingify" actions or processes. Here, the semantic notion is consistent with Lakoff and Johnson's (1980) characterization of an ontological metaphor, which "allows us to pick out parts of our experience and treat them as discrete entities or substances of a uniform kind" (p. 25). When used as an adjective, "power" transfers the same properties attributed to its noun state to some other noun.

The transcripts of all ads in the two samples revealed that approximately one-fifth (21 percent) of the ads for boy-oriented toys contained the words "power" or "powerful." Of 45 power words, 28 were nouns, for example, "pack secret power," "more power than before," "home run power," "get the powers," "pump up the power," and "power you're packin." "Power" was used as an adjective 17 times, for example "pow-pow-power wheels" "power pack," "power bat," and "power base." "Power" as an adjective was used in the names for two toys: "POWER RANGERS ZEO" and "SUPER SONIC POWER CRASH PIT RACERS."

"Power" was heard only once in girloriented toys ads. Ironically, the only instance of a power word in girl-oriented ads was in the commercial for "BARBIE SUN JAMMER CAR." Here the word came at the end of the 30 seconds when the manufacturer was identified as "Power Wheels." Toy makers and their advertisers either make no effort to associate or may consciously avoid associating girl-toys with power or their potential to transfer power to their users.

\section{Implications}

The ads we analyzed along with more informal viewing and re-viewing of many television commercials directed to children raise serious questions about the ongoing role of television in gender enculturation, especially among very young children. Kids love commercials, and it is a rare child who does not watch them with rapt attention. Despite the messages that youngsters receive from parents and teachers about the greater equity of the sexes in education, sports, jobs, and so forth, polarized patterns of language continue to be modeled in consumer culture directed to children.

One interpretation of the themes found in the advertisements we analyzed is that they are a response to what strategically savvy advertisers know about selling to boys and girls. From the perspective of what interests kids, there is evidence pointing to gender differences in what kids value in television programs. Valkenburg \& Janssen (1999), for example, found differences in what boys and girls in the first- through fourth-grades found interesting in programs: boys favored programs with action and violence more than did girls, and girls favored programs with innocuous content and comprehensibility more than did boys. These interests likely carry over to advertising content. Even if this is the case, the sharply polarized gender models offered up in ads coupled with the verbal images created for girls and boys recycle conventional gender ideology rather than minimizing or challenging gender stereotyping.

Gender polarization in ads may persist for many reasons, but several possibilities seem likely. First, because we are dealing with a commercial enterprise, past formulas that work will likely 
endure, unless there is clear evidence that these formulaic approaches fail to be effective with the target audience. From a marketing perspective, change for the sake of social progressiveness may simply be too risky.

From a marketing perspective, it is also more profitable for producers of children's toys to create separate toys for boys and girls as a way of placing more items in the marketplace. If boys and girls are presented with different toys, they will likely believe that it is appropriate to buy and associate themselves with different toys. This type of market segmentation primes children for adult consumer behavior and is part of the cultural making of gendered natives that Bem (1993) describes.

The appeal to gender polarization in advertising directed to children prepares the child consumer for the barrage of gender specific products and appeals that have become commonplace in the adult consumer marketplace. In a reciprocal manner, the polarized gender strategy in presentations to children places their world of goods in the context of the larger world of goods that are visible and audible in the adult domain-goods that solidify the separation of activities, voice, interests, and appearances of women and men. Selling gender dichotomies to children primes the economic pump for the substantially larger profits to be had in the sharply divided, sex-linked consumer market of adult products. Many of the adult products that children are seeing and hearing about will be meaningful because the scripts for gender and consumption have been learned in the process of the child becoming a gendered native of her or his culture.

Although the finding that gender is heavily used in advertising directed to children (or to adults for that matter) is in itself not surprising, our research offers insight about how language elements contribute to the construction of gender. Language patterns are powerful symbolic resources for situating gender identities. Yet, language patterns often go unnoticed or are considered less important than the material aspects of gender identity. What we have added to the knowledge about advertising to children is a map of how gendered language features that have been the subject of extensive sociolinguistic inquiry are given voice as part of the strategy for selling consumerism to kids. Television advertising offers a site where gender specific polarization in toys can be exploited not just visually but through manipulation of what is culturally recognizable as the gendered voice. Television serves as a pervasive "secondary source" for how boys and girls (and men and women) speak (Romaine, 1999), thus perpetuating the cycle of reciprocal influence back and forth between folk-linguistics (what people believe about language use) and language as actually used. The verbal images of boys and girls speaking, as those images are attached to gender differentiated commodities, symbolically undermine more nuanced cultural ideas about gender role changes that have currency in education and at least some parental guidance.

In our study, we addressed several dimensions of language that are steeped with gender semantics. There are likely more ways in which the 15 and 30 second "commercial" packages of ideology create verbal imaging of gender. It would be useful to examine, for example, the relation of verbal utterances and visual features in the ads, such as placement of the actors, paralanguage, and nonverbal aspects (head tilts, arm 
movements, posture, facial expressions) of boy and girl actors.

Although not addressed in this analysis, race and ethnicity are also voiced in alarming ways in television's appeal to kids as consumers. For example, the only instance in our samples of an ad exclusively featuring a black boy depicts him speaking a version of rapvernacular dialect, and the few ads with visibly Asian children rarely give them any voice at all. An examination of ads directed to children that focuses on the appropriation of "cultural diversity" would be a valuable addition to scholarship and media literacy programs.

After watching and listening to hundreds of television commercials directed to kids, the voices begin to inhabit one's head. Many are memo- rable-to us but more so to kids who are their targets. For those concerned about teaching gender sensitivity to children, the messages from toy advertisers are stiff competition. In our ears we hear a sickeningly sweet voice singing "Potty Dotty" as girls are instructed to practice mothering, and a growling voice-over proclaiming the aggressive power of "Electronic $\mathrm{Ka}$ rate Fighters" who are swinging at each other in an out-of-control scene that cuts back and forth between humans and toys. These voices and images and many others like them constitute part of kids' culture. Clearly, as we teach children to be media literate, that literacy training should include tuning their ears to the images of gender conveyed through language.

\section{References}

Alexander, A., \& Morrison, M. A. (1995). Electric toyland and the structures of power: An analysis of critical studies on children as consumers. Critical Studies in Mass Communication, 12, 344-353.

Allan, K., \& Coltrane, S. (1996). Gender displaying television commercials: A comparative study of television commercials in the 1950s and 1980s. Sex Roles, 35, 185-203.

Bem, S. L. (1993). The lenses of gender: Transforming the debate on sexual inequality. New Haven: Yale University Press.

Dobrow, J. R., \& Gidney, C. L. (1998). The good, the bad, and the foreign: The use of dialect in children's animated television. The Annals of the American Academy of Political and Social Science, 557, 105-119.

Furnham, A., Abramsky, S., \& Gunter, B. (1997). A cross-cultural content analysis of children's television advertisements. Sex Roles, 37, 91-99.

Goldman, R., \& Papson, S. (1996). Sign wars: The cluttered landscape of advertising. New York: Guilford Press.

John, D. R. (1999). Through the eyes of a child: Children's knowledge and understanding of advertising. In M. C. Macklin \& L. Carlson (Eds.), Advertising to children: Concepts and controversies (pp. 3-26). Thousand Oaks, CA: Sage Publications.

Johnson, F. L. (1996). Friendships among women: Closeness in dialogue. In J. T. Wood (Ed.), Gendered relationships. Mountain View, CA: Mayfield.

Johnson, F. L. (2000). Speaking culturally: Language diversity in the United States. Thousand Oaks, CA: Sage Publications.

Kapur, J. (1999). Out of control: Television and the transformation of childhood in late capitalism. In M. Kinder (Ed.), Kids' media culture (pp. 122-136). Durham: Duke University Press.

Kline, S. (1993). Out of the garden: Toys and children's culture in the age of TV marketing. London: Verso. 
Kunkle, D., \& Gantz, W. (1992). Children's television advertising in the multichannel environment. Journal of Communication, 42, 134-152.

Leonhardt, D., \& Kerwin, K. (1997, 30 June). Hey kid, buy this! Business Week, pp. 61-67.

Lakoff, G., \& Johnson, M. (1980). Metaphors we live by. Chicago: University of Chicago Press.

Macklin, M. C., \& Carlson, L. (Eds.). (1999). Advertising to children: Concepts and controversies. Thousand Oaks, CA: Sage Publications.

McNeal, J. U. (1998). Tapping the three kids' markets. American Demographics, 20 (April), 36-41.

Meijer, I. C. (1998). Advertising citizenship: An essay on the performative power of consumer culture. Media, Culture ES Society, 20, 235-249.

Myers, G. (1999). Ad worlds: Brands, media, audiences. New York: Oxford University Press.

Pecora, N. (1995). Children and television advertising from a social science perspective. Critical Studies in Mass Communication, 12, 354-364.

Romaine, S. (1999). Communicating gender. Mahwah, NJ: Lawrence Erlbaum.

Smith, L. J. (1994). A content analysis of gender differences in children's advertising. Journal of Broadcasting E Electronic Media, 323-337.

Thompson, T. L., \& Zerbinos, E. (1995). Gender roles in animated cartoons: Has the picture changed in 20 years? Sex Roles, 32, 651-673.

Valkenburg, P. M., \& Janssen, S. C. (1999). What do children value in entertainment programs? A cross-cultural investigation. Journal of Communication, 49, 3-21.

Walker, K. (1994). Men, women, and friendship: What they say, what they do. Gender and Society, $8,246-265$.

Welch, R. L., Huston-Stein, A., Wright, J. C., \& Plehal, R. (1979). Subtle sex-role cues in children's commercials. Journal of Communication, 29, 202-209.

West, C. (1992). Rethinking "sex differences" in conversational topics. Advances in Group Processes, 9, 131-162.

White, M. (1999). Mattel CEO may be ousted for loss [On-line]. Available: http://www.tcpalm.com/ business/v05smatt.shtml [2000, May 23].

Woodard, E. H. IV. (2000). Media in the home 2000: The fifth annual survey of parents and children. The Annenberg Public Policy Center, Survey Series No. 7 [On-line]. Available: http://appcpenn.org [2002, July 15].

Young, B. M. (1990). Television advertising and children. New York: Oxford University Press.

Received February 5, 2001

Final revision received March 1, 2002

Accepted June 5, 2002 